\title{
Association of High Neutrophil-to-Lymphocyte Ratio With Poor Outcomes of Pembrolizumab Therapy in High-PD-L1-expressing Non-small Cell Lung Cancer
}

\author{
TSUKASA HASEGAWA ${ }^{1}$, NORIKO YANAGITANI ${ }^{1}$, HIROFUMI UTSUMI $^{2}$, HIROSHI WAKUI $^{2}$, \\ HIROAKI SAKAMOTO ${ }^{1}$, TAKEHIRO TOZUKA ${ }^{1}$, HIROSHI YOSHIDA ${ }^{1}$, YOSHIAKI AMINO ${ }^{1}$, \\ SHINYA UEMATSU ${ }^{1}$, TAKAHIRO YOSHIZAWA ${ }^{1}$, KEN UCHIBORI ${ }^{1}$, SATORU KITAZONO ${ }^{1}$, \\ ATSUSHI HORIIKE ${ }^{1}$, TAKESHI HORAI ${ }^{1}$, KAZUYOSHI KUWANO $^{2}$ and MAKOTO NISHIO ${ }^{1}$ \\ ${ }^{1}$ Department of Thoracic Medical Oncology, \\ the Cancer Institute Hospital of Japanese Foundation for Cancer Research, Tokyo, Japan; \\ ${ }^{2}$ Division of Respiratory Diseases, Department of Internal Medicine, \\ the Jikei University School of Medicine, Tokyo, Japan
}

\begin{abstract}
Background: This study aimed to determine whether the neutrophil-to-lymphocyte ratio (NLR) reflected poor treatment benefits in patients with tumor proportion score (TPS) $\geq 50 \%$ and who under went first-line pembrolizumab monotherapy. Patients and Methods: This study retrospectively analyzed patients with untreated stage III/IV or recurrent non-small cell lung cancer (NSCLC) with $T P S \geq 50 \%$ and who received pembrolizumab monotherapy at two hospitals between February 2017 and April 2019. The NLR was calculated from pre-treatment complete blood counts. Results: A total of 51 previously untreated patients with NSCLC who had TPS $\geq 50 \%$ and who underwent pembrolizumab monotherapy were evaluated. Multivariate analysis revealed that high NLR, Eastern Cooperative Oncology Group performance status $(P S) \geq 2$, stage IV or recurrent cancer, and TPS $=50-74 \%$ were significantly and independently associated with poor progression-free survival. Moreover, high NLR and PS $\geq 2$ were significantly associated with short overall survival. Conclusion: A high pre-treatment NLR was associated with significantly short progression-free and overall survival in previously untreated patients with NSCLC with high expression of programmed cell-death ligand 1 treated with pembrolizumab monotherapy.
\end{abstract}

Correspondence to: Makoto Nishio, MD, Ph.D., Department of Thoracic Medical Oncology, The Cancer Institute Hospital of Japanese Foundation for Cancer Research, 3-8-31 Ariake, Koto-ku, Tokyo 135-8550, Japan. Tel: +81 335200111, Fax: +81 335200141, e-mail:mnishio@jfcr.or.jp

Key Words: Non-small cell lung cancer, PD1, pembrolizumab, neutrophil-to-lymphocyte ratio, predictor.
Lung cancer remains the leading cause of cancer-related death worldwide (1) despite dramatic advances in cutting edge and radical treatments, including targeted therapies for advanced non-small cell lung cancer (NSCLC). Targeted therapies have improved the survival of patients with driver oncogenes and are standard first-line therapies. However, for patients without driver oncogenes, improvements in survival were minimal until immunotherapeutic alternatives became available.

Therapeutic agents such as nivolumab, pembrolizumab, and atezolizumab, which are antibodies that target programmed death 1 (PD1) or its ligand (PD-L1), have significantly improved survival compared with docetaxel as a second-line treatment for advanced NSCLC without any selection or with a PD-L1 tumor proportion score (TPS) of $\geq 1 \%$ (2-5). However, in studies with the aforementioned results, the objective response was low at $15 \%$, indicating that only few patients benefited from the treatment, warranting the need for precise patient selection and additional efficacy studies. Selection of patients based on PD-L1 expression in tumor tissue is perhaps the best biomarker for treating advanced NSCLC with anti-PD1/L1 antibody. Two phase III studies compared pembrolizumab monotherapy with platinum-based chemotherapy as the firstline treatment in patients with untreated NSCLC who had TPS $\geq 50 \%$ [KEYNOTE-024 (6)] and $>1 \%$ [KEYNOTE-042 (7)]. Pembrolizumab monotherapy significantly prolonged overall survival (OS) and progression-free survival (PFS) and has become a standard, first-line treatment. However, in KEYNOTE-042 (7), the PFS and OS curves of patients with TPS $\geq 50 \%$ suggested that certain patients were unlikely to benefit from pembrolizumab monotherapy. The KEYNOTE189 and KEYNOTE-407 studies (8) revealed that pembrolizumab plus platinum-doublet chemotherapy as a first-line treatment significantly prolonged OS and PFS 
compared with chemotherapy alone, regardless of PD-L1 TPS, in patients with squamous NSCLC and those with nonsquamous NSCLC. Thus, pembrolizumab monotherapy or pembrolizumab plus platinum-doublet chemotherapy are currently available as first-line NSCLC treatments for patients with TPS $\geq 50 \%$.

The characteristics of patients that define the use of combination therapy are unclear. This may be resolved by the identification of markers that indicate poor treatment benefits from first-line pembrolizumab monotherapy in patients with NSCLC who have TPS $\geq 50 \%$ to avoid chemotherapy toxicity and excessive combination therapy.

The baseline counts of peripheral blood cells such as neutrophils, lymphocytes, eosinophils and neutrophil-tolymphocyte ratio (NLR) are reportedly associated with outcome in patients with melanoma and NSCLC treated with antibodies to PD1 (9). Thus, the present study aimed to investigate the relationship between peripheral blood counts, including NLR, and the efficacy of first-line pembrolizumab monotherapy in patients with NSCLC who have TPS $\geq 50 \%$.

\section{Patients and Methods}

Patients. We retrospectively reviewed the medical records of all patients with pathologically confirmed, untreated stage III/IV or recurrent NSCLC who had TPS $\geq 50 \%$ and who received pembrolizumab monotherapy as first-line treatment at the Cancer Institute Hospital of Japanese Foundation for Cancer Research and the Jikei University School of Medicine between February 2017 and April 2019. Patients were ineligible if they had sensitizing epidermal growth factor receptor mutation and the rearrangement fusion of anaplastic lymphoma kinase; active autoimmune disease for which they had received systemic treatment; or active interstitial lung disease. Pembrolizumab was intravenously administered at a dose of $200 \mathrm{mg}$ every 3 weeks. The cut-off for the follow-up period was April 30, 2019. TPS was determined based on PD-L1 immunoassay performed at a certified commercial laboratory (SRL Inc., Tokyo, Japan) using monoclonal antibody against PD-L1 (22C3 PharmDx; Agilent Technologies, Santa Clara, CA, USA). The study was performed according to protocols approved by the Institutional Review Boards of the participating hospitals (approval number: 2019-1085).

Data collection. Clinicopathological features and treatment history data were extracted from the medical records and were updated as of April 30, 2019. Tumor response was assessed using computed tomography every 6-8 weeks according to the Response Evaluation Criteria in Solid Tumors, version 1.1 (10). PFS was measured from the time of initiating pembrolizumab treatment to clinical or radiographic progression or death from any cause. OS was measured from the time of initiating pembrolizumab treatment to death from any cause. Data for differential blood counts and serum C-reactive protein (CRP) levels and high lactate dehydrogenase (LDH) levels within 7 days prior to treatment initiation were also extracted. White blood cell count (WBC), absolute neutrophil count (ANC), absolute lymphocyte count (ALC), serum LDH level, CRP level, and albumin level at baseline were analysed. WBC, ANC, LDH and CRP levels were categorized according to the upper limit of normality, and ALC and albumin levels were categorized according to the lower limit of normality. NLR was the ratio of ANC to ALC; CRP-to-albumin ratio (CAR) was also determined.

Statistical analysis. Clinically important factors, including age $(<75$ $v s . \geq 75$ years), sex, Eastern Cooperative Oncology Group performance status (PS; 0 or 1 vs. 2), smoking status (never vs. former or current), stage (III $v s$. IV or recurrent), TPS (50-74\% vs. $75-100 \%$ ), metastatic sites, and baseline peripheral blood counts were used as variables. The Fisher's exact test or Mann-Whitney $U$-test was used to evaluate the association of baseline variables with disease control [progressive disease (PD) vs. non-PD]. KaplanMeier analysis of PFS and OS was conducted; moreover, differences between pairs of variables were assessed using the log-rank test. Hazard ratios (HR) and $95 \%$ confidence intervals (CI) were calculated using the univariate Cox proportional hazard model. Parameters with a value of $p<0.05$ in the univariate analysis were selected for inclusion in the multivariate analysis. All data were analyzed using EZR on R commander version 1.27 (Saitama Medical Center, Jichi Medical University, Saitama, Japan).

\section{Results}

Patient characteristics. We included 51 patients who were treated with pembrolizumab as the first-line treatment. Baseline characteristics and peripheral blood counts of these patients are shown in Table I. Of all patients, 40 (78.4\%) were male and a majority had PS of 0 or 1 (90.2\%); moreover, $86.3 \%$ had smoked or were current smokers. The median age was 70.0 (range $=35-86$ ) years. Thirty-seven $(72.5 \%)$ patients had non-squamous NSCLC and $44(86.3 \%)$ had stage IV cancer or recurrence after surgery. While the TPS of all patients was $\geq 50 \%$, that of $33(64.7 \%)$ patients was $\geq 75 \%$. Except for one patient with c-ros oncogene 1 , receptor tyrosine kinase fusion gene, none of the patients had a driver mutation. Ten (19.6\%) patients had brain metastasis.

The median \pm SD NLR was 5.25 \pm 5.25 and CAR was 1.04 \pm 1.29 . The cut-off values for NLR and CAR, analyzed using receiver operating characteristic curves, were 4.56 and 1.12 , respectively. Of all 51 patients, $14(27.5 \%)$ had a high NLR and 16 (31.4\%) had a high CAR. The objective response rate of pembrolizumab administered to 51 patients was $41.2 \%$. PD was observed in $21(41.2 \%)$ patients. The number of patients with stage III cancer and TPS $>75 \%$ in the non-PD group was significantly higher than that in the PD group. There was a significant difference between the PD and non-PD groups regarding peripheral blood counts, ANC, NLR, and serum LDH level.

The median follow-up duration was 9.5 (range=0.5-25.6) months, and $12(23.5 \%)$ patients were undergoing pembrolizumab treatment. The median PFS was 4.4 $(95 \% \mathrm{CI}=1.9-8.4)$ months and median OS was 19.1 months (95\% CI=8.3 months-not reached). 
Table I. Patient characteristics $(N=51)$.

\begin{tabular}{|c|c|c|c|c|c|}
\hline & & \multicolumn{4}{|c|}{ Group } \\
\hline & & Total & Non-PD (N=30) & $\mathrm{PD}(\mathrm{N}=21)$ & $p$-Value \\
\hline \multirow[t]{2}{*}{ Age, years } & Median (range) & $70.0(35-86)$ & $70.0(39-86)$ & $69.0(35-82)$ & \\
\hline & $\geq 75$ Years & $16(31.4)$ & $12(40.0)$ & $4(19.0)$ & 0.137 \\
\hline \multirow[t]{2}{*}{ Gender, n (\%) } & Male & $40(78.4)$ & $24(80.0)$ & $16(76.2)$ & 0.744 \\
\hline & Female & $11(21.6)$ & $6(20.0)$ & $5(23.8)$ & \\
\hline \multirow[t]{2}{*}{ PS, n (\%) } & $0-1$ & $46(90.2)$ & $29(96.7)$ & $27(81.0)$ & 0.146 \\
\hline & $\geq 2$ & $5(9.8)$ & $1(3.3)$ & $4(19.0)$ & \\
\hline \multirow[t]{2}{*}{ Smoking status, n (\%) } & Current or former & $44(86.3)$ & $25(83.3)$ & $19(90.5)$ & 0.685 \\
\hline & Never & $7(13.7)$ & $5(16.7)$ & $1(9.5)$ & \\
\hline \multirow{2}{*}{ deHistology, n (\%) } & Non-squamous cell carcinoma & $37(72.5)$ & $22(73.3)$ & $15(71.4)$ & 1.000 \\
\hline & Squamous cell carcinoma & $14(27.5)$ & $8(26.7)$ & $6(28.6)$ & \\
\hline \multirow[t]{3}{*}{ Driver oncogene status, n (\%) } & $E G F R$ sensitizing mutation & $0(0-0)$ & $0(0-0)$ & $0(0-0)$ & - \\
\hline & $A L K$ rearrangement fusion & $0(0-0)$ & $0(0-0)$ & $0(0-0)$ & \\
\hline & ROS1 rearrangement fusion & $1(2.0)$ & $1(3.3)$ & $0(0-0)$ & \\
\hline \multirow[t]{2}{*}{ Stage, n $(\%)$} & III & $7(13.7)$ & $7(23.3)$ & $0(0-0)$ & 0.033 \\
\hline & IV recurrent & $44(86.3)$ & $23(76.7)$ & $21(100.0)$ & \\
\hline \multirow{2}{*}{ TPS, n (\%) } & $50-74 \%$ & $18(35.3)$ & $6(20.0)$ & $12(57.1)$ & 0.009 \\
\hline & $75-100 \%$ & $33(64.7)$ & $24(80.0)$ & $9(42.9)$ & \\
\hline Brain metastases, n (\%) & Yes & $10(19.6)$ & $6(20.0)$ & $4(19.0)$ & 1.000 \\
\hline \multicolumn{6}{|l|}{ Peripheral blood biomarkers } \\
\hline $\mathrm{WBC}, \mathrm{n}(\%)$ & $\geq 8,600 / \mathrm{mm}^{3}$ & $21(41.2)$ & $9(30.0)$ & $12(57.1)$ & 0.083 \\
\hline $\mathrm{ANC}, \mathrm{n}(\%)$ & $\geq 6,300 / \mathrm{mm}^{3}$ & $15(29.4)$ & $5(16.7)$ & $10(47.6)$ & 0.028 \\
\hline ALC, n (\%) & $\leq 1,000 / \mathrm{mm}^{3}$ & $9(17.6)$ & $5(16.7)$ & $4(19.0)$ & 1.000 \\
\hline NLR, n (\%) & $\geq 4.56$ & $14(27.5)$ & $4(13.3)$ & $10(47.6)$ & 0.011 \\
\hline Serum LDH, n (\%) & $>222 \mathrm{U} / 1$ & $20(39.2)$ & $8(26.7)$ & $12(57.1)$ & 0.042 \\
\hline CRP, n (\%) & $>0.14 \mathrm{mg} / \mathrm{dl}$ & $44(86.3)$ & $27(90.0)$ & $17(81.0)$ & 0.427 \\
\hline Albumin, n (\%) & $<4.0 \mathrm{~g} / \mathrm{dl}$ & $43(84.3)$ & $25(83.3)$ & $18(85.3)$ & 1.000 \\
\hline $\mathrm{CAR}, \mathrm{n}(\%)$ & $\geq 1.12$ & $16(31.4)$ & $7(23.3)$ & $9(42.9)$ & 0.220 \\
\hline
\end{tabular}

PD: Progressive disease; PS: performance status; EGFR: epidermal growth factor receptor; ALK: the rearrangement fusion of anaplastic lymphoma kinase; ROS1: c-ros oncogene 1, receptor tyrosine kinase; TPS: tumor proportion score; WBC: white blood cell; ANC: absolute neutrophil count; ALC: absolute lymphocyte count; NLR: neutrophil-to-lymphocyte ratio; LDH: lactate dehydrogenase; CRP: C-reactive protein; CAR: C-reactive protein-to-albumin ratio.

Univariate and multivariate analysis of biomarkers for determining survival outcome. We examined peripheral blood parameters for use as potential prognostic factors to identify a biomarker of poor treatment benefit of pembrolizumab as first-line monotherapy (Table II). Univariate Cox proportional hazard regression analysis of the prognostic factors revealed that high $(\geq 4.56)$ NLR was associated with a significantly short PFS (median: $1.2 v s .6 .5$ months; $p=0.004$ ) and OS (median: 4.8 months $v s$. not reached; $p=0.004)$ compared with low NLR. The KaplanMeier curves of PFS and OS according to NLR are shown in Figure 1 .

PS $(\geq 2)$ was significantly associated with short PFS $(\mathrm{HR}=3.56,95 \% \mathrm{CI}=1.35-9.38 ; p=0.010)$ and $\mathrm{OS}(\mathrm{HR}=3.79$; $95 \% \mathrm{CI}=1.27-11.34 ; \quad p=0.017)$. TPS of $50-74 \%$ was associated with significantly short PFS $(\mathrm{HR}=2.12$, $95 \% \mathrm{CI}=1.10-4.09 ; p=0.025)$ but not with significantly better $\mathrm{OS}(\mathrm{HR}=1.24,95 \% \mathrm{CI}=0.53-2.86 ; p=0.619)$. High
WBC $(\mathrm{HR}=2.53,95 \% \mathrm{CI}=1.30-4.92 ; p=0.006)$ and serum LDH level $(\mathrm{HR}=1.25,95 \% \mathrm{CI}=1.15-4.18 ; p=0.017)$ were significantly associated with short PFS. High ANC was significantly associated with short $\mathrm{OS} \quad(\mathrm{HR}=3.03$, 95\% $\mathrm{CI}=1.49-6.15 ; \quad p=0.002)$ and $\mathrm{PFS} \quad(\mathrm{HR}=3.73$, $95 \% \mathrm{CI}=1.59-8.74 ; p=0.002)$.

Multivariate analysis was performed using risk factors associated with patient survival among all baseline characteristics: PS, TPS and stage (Table III). The multivariate analysis of PFS revealed that high NLR $(\mathrm{HR}=2.214,95 \% \mathrm{CI}=1.04-4.74 ; p=0.040), \mathrm{PS} \geq 2(\mathrm{HR}=3.889$, $95 \% \mathrm{CI}=1.16-13.01 ; p=0.027)$, stage IV or recurrent cancer $(\mathrm{HR}=3.407,95 \% \mathrm{CI}=1.09-10.65 ; p=0.035)$, and TPS $50-74 \%$ $(\mathrm{HR}=2.448,95 \% \mathrm{CI}=1.26-4.77 ; p=0.008)$ were significantly associated with short PFS. The multivariate analysis of OS revealed that high $\mathrm{NLR}(\mathrm{HR}=3.225,95 \% \mathrm{CI}=1.34-7.76$; $p=0.009)$ and $\mathrm{PS} \geq 2 \quad(\mathrm{HR}=3.873,95 \% \mathrm{CI}=1.10-13.60$; $p=0.035)$ were significantly associated with short OS. 
Table II. Univariable Cox proportional-hazards model for progression-free (PFS) and overall (OS) survival.

\begin{tabular}{|c|c|c|c|c|c|c|c|c|}
\hline & & $\mathrm{n}$ & $\begin{array}{c}\text { Median PFS } \\
(95 \% \mathrm{CI})\end{array}$ & HR $(95 \% \mathrm{CI})$ & $p$-Value & $\begin{array}{c}\text { Median OS } \\
(95 \% \mathrm{CI})\end{array}$ & HR $(95 \% \mathrm{CI})$ & $p$-Value \\
\hline \multirow[t]{2}{*}{ Age } & $\geq 75$ Years & 16 & $6.0(1.5-10.4)$ & $0.98(0.50-1.92)$ & 0.953 & 19.1 (7.2-NE) & $0.84(0.34-2.03)$ & 0.691 \\
\hline & $<75$ Years & 35 & $4.0(1.2-8.4)$ & & & NE (5.6-NE) & & \\
\hline \multirow[t]{2}{*}{ Gender } & Male & 40 & $4.7(1.9-8.4)$ & $0.91(0.43-1.94)$ & 0.815 & NE (8.6-NE) & $0.81(0.32-2.07)$ & 0.661 \\
\hline & Female & 11 & $4.0(1.0-10.4)$ & & & 19.1 (1.9-NE) & & \\
\hline \multirow[t]{2}{*}{ PS } & $\geq 2$ & 5 & $0.9(0.5-\mathrm{NE})$ & $3.56(1.35-9.38)$ & 0.010 & $1.5(0.5-\mathrm{NE})$ & $3.79(1.27-11.34)$ & 0.017 \\
\hline & $0-1$ & 46 & $5.3(2.2-10.4)$ & & & $\mathrm{NE}(8.6-\mathrm{NE})$ & & \\
\hline \multirow[t]{2}{*}{ Smoking status } & Current or former & 44 & $4.3(1.2-8.4)$ & $1.15(0.48-2.75)$ & 0.755 & $16.1(5.6-\mathrm{NE})$ & $2.58(0.60-11.09)$ & 0.204 \\
\hline & Never & 7 & $8.2(1.5-\mathrm{NE})$ & & & NE (8.3-NE) & & \\
\hline \multirow[t]{2}{*}{ Histology } & Non-squamous & 37 & $4.4(1.5-8.4)$ & $1.31(0.62-2.78)$ & 0.478 & $16.1(7.2-\mathrm{NE})$ & $0.82(0.33-2.00)$ & 0.661 \\
\hline & Squamous & 14 & $6.3(0.9-\mathrm{NE})$ & & & $19.1(1.5-\mathrm{NE})$ & & \\
\hline \multirow[t]{2}{*}{ Stage } & IV recurrent & 44 & $4.1(1.2-6.2)$ & $2.12(0.75-5.99)$ & 0.157 & $16.1(6.0-\mathrm{NE})$ & $1.98(0.46-8.45)$ & 0.356 \\
\hline & III & 7 & 10.4 (3.1-NE) & & & 19.1 (3.1-NE) & & \\
\hline \multirow[t]{2}{*}{ TPS } & $50-74 \%$ & 18 & $1.7(0.9-6.2)$ & $2.12(1.10-4.09)$ & 0.025 & $13.3(3.8-\mathrm{NE})$ & $1.24(0.53-2.86)$ & 0.619 \\
\hline & $75-100 \%$ & 33 & $5.6(3.7-18.9)$ & & & $\mathrm{NE}(8.0-\mathrm{NE})$ & & \\
\hline \multirow[t]{2}{*}{ Brain metastases } & Yes & 10 & $4.7(1.0-6.5)$ & $1.15(0.52-2.51)$ & 0.734 & $7.2(1.9-\mathrm{NE})$ & $1.34(0.49-3.64)$ & 0.569 \\
\hline & No & 41 & $4.4(1.5-10.4)$ & & & $19.1(8.6-\mathrm{NE})$ & & \\
\hline \multirow[t]{2}{*}{ WBC } & $\geq 8,600 / \mathrm{mm}^{3}$ & 21 & $1.2(0.9-4.9)$ & $2.53(1.30-4.92)$ & 0.006 & 13.3 (2.4-NE) & $2.27(0.99-5.25)$ & 0.054 \\
\hline & $<8,600 / \mathrm{mm}^{3}$ & 30 & $7.4(4.0-18.9)$ & & & NE (8.6-NE) & & \\
\hline \multirow[t]{2}{*}{ ANC } & $\geq 6,300 / \mathrm{mm}^{3}$ & 15 & $1.0(0.8-3.7)$ & $3.03(1.49-6.15)$ & 0.002 & $3.8(1.8-\mathrm{NE})$ & $3.73(1.59-8.74)$ & 0.002 \\
\hline & $<6,300 / \mathrm{mm}^{3}$ & 36 & $7.4(4.0-15.4)$ & & & $\mathrm{NE}(9.5-\mathrm{NE})$ & & \\
\hline \multirow[t]{2}{*}{ ALC } & $\leq 1,000 / \mathrm{mm}^{3}$ & 9 & $3.1(0.5-4.3)$ & $1.75(0.80-3.84)$ & 0.163 & 16.1 (0.9-NE) & $1.72(0.63-4.66)$ & 0.290 \\
\hline & $>1,000 / \mathrm{mm}^{3}$ & 42 & $4.7(1.9-10.4)$ & & & 19.1 (8.3-NE) & & \\
\hline \multirow[t]{2}{*}{ NLR } & $\geq 4.56$ & 14 & $1.2(0.8-5.6)$ & $2.82(1.40-5.66)$ & 0.004 & $4.8(1.5-\mathrm{NE})$ & $3.56(1.51-8.38)$ & 0.004 \\
\hline & $<4.56$ & 37 & $6.5(4.0-15.4)$ & & & NE (13.3-NE) & & \\
\hline \multirow[t]{2}{*}{ Serum LDH } & $>222 \mathrm{U} / 1$ & 20 & $1.1(0.9-5.6)$ & $2.19(1.15-4.19)$ & 0.017 & $7.2(1.8-\mathrm{NE})$ & $2.24(0.97-5.19)$ & 0.059 \\
\hline & $\leq 222 \mathrm{U} / 1$ & 31 & $8.4(3.7-15.4)$ & & & NE (8.6-NE) & & \\
\hline \multirow[t]{2}{*}{ CRP } & $>0.14 \mathrm{mg} / \mathrm{dl}$ & 44 & $4.7(1.9-8.4)$ & $1.05(0.41-2.70)$ & 0.915 & $19.1(6.0-\mathrm{NE})$ & $1.40(0.42-4.75)$ & 0.585 \\
\hline & $\leq 0.14 \mathrm{mg} / \mathrm{dl}$ & 7 & $2.2(0.9-\mathrm{NE})$ & & & NE (2.8-NE) & & \\
\hline \multirow[t]{2}{*}{ Albumin } & $<4.0 \mathrm{~g} / \mathrm{dl}$ & 43 & $4.4(1.9-6.5)$ & $1.49(0.58-3.83)$ & 0.411 & $13.3(5.6-\mathrm{NE})$ & $5.96(0.80-44.33)$ & 0.081 \\
\hline & $\geq 4.0 \mathrm{~g} / \mathrm{dl}$ & 8 & $9.8(0.5-\mathrm{NE})$ & & & NE (8.3-NE) & & \\
\hline \multirow[t]{2}{*}{ CAR } & $\geq 1.12$ & 16 & $3.1(0.9-8.4)$ & $1.48(0.75-2.90)$ & 0.256 & $3.8(1.5-\mathrm{NE})$ & $1.92(0.80-4.61)$ & 0.143 \\
\hline & $<1.12$ & 35 & $5.6(2.2-11.3)$ & & & 19.1 (8.6-NE) & & \\
\hline
\end{tabular}

CI: Confidence interval; HR: hazard ratio; PS: Eastern Cooperative Oncology Group performance status; TPS: tumor proportion score; WBC: white blood cell; ANC: absolute neutrophil count; ALC: absolute lymphocyte count; NLR: neutrophil-to-lymphocyte ratio; LDH: lactate dehydrogenase; CRP: C-reactive protein; CAR: C-reactive protein-to-albumin ratio; NE: not estimable.

\section{Discussion}

Our study showed that high NLR $(\geq 4.56)$ at the pretreatment stage was independently and significantly associated with short PFS and OS of patients with NSCLC and who had TPS $\geq 50 \%$ and underwent pembrolizumab monotherapy as first-line treatment. In fact, the usefulness of NLR as a predictive and prognostic biomarker in patients with various solid tumors who received immune checkpoints inhibitors has been investigated (11-13). A meta-analysis of 16 studies comprising 1,700 patients with NSCLC demonstrated that elevated NLR was associated with short PFS and OS following treatment with PD1/PD-L1 inhibitors (14). However, as a limitation, this meta-analysis did not include PD1 antibody as the first-line treatment for patients with TPS $\geq 50 \%$.
To the best of our knowledge, there is a lack of studies evaluating the association between the efficacy of anti-PD1/L1 and NLR in patients with high PD-L1-expressing NSCLC. Therefore, we explored whether NLR might serve as a specific marker for assessing the efficacy of anti-PD1 as first-line treatment for patients with NSCLC who had TPS $\geq 50 \%$. We found that NLR was significantly associated with PFS and OS using univariate and multivariate analyses. However, TPS was significantly associated with PFS but not with OS. Our results indicate that the feasibility of determining NLR in clinical practice deems NLR as a potential biomarker to predict poor outcomes of anti-PD1 monotherapy.

Biologically, NLR reflects systemic inflammation and potentially represents the balance of the immune system in a malignant setting. Inflammation is known to be associated with the development and progression of cancer (15). 

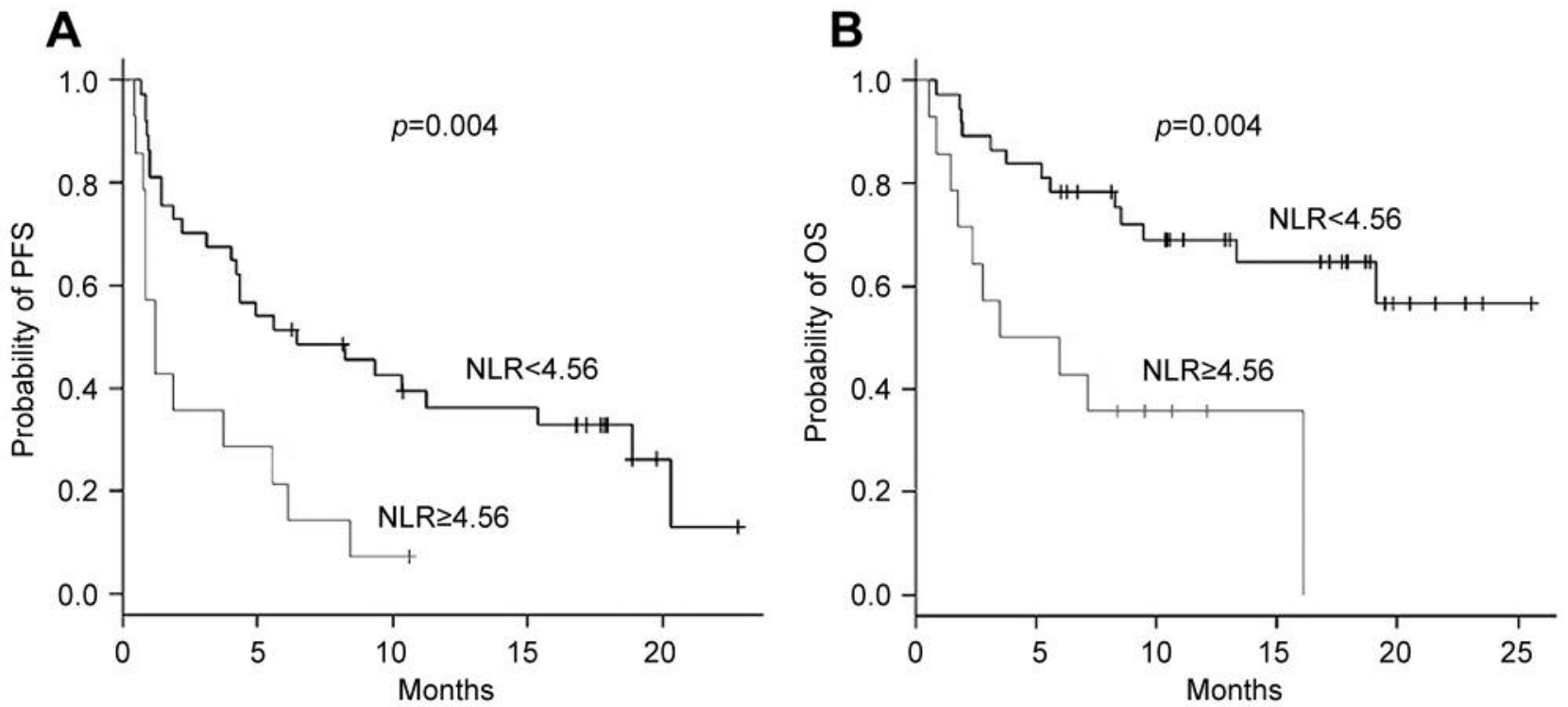

Figure 1. Kaplan-Meier curves of progression-free (PFS; A) and overall (OS;B) survival according to neutrophil-to-lymphocyte ratio (NLR). A high ( $\geq 4.56)$ NLR was associated with significantly short PFS and OS.

Table III. Multivariable Cox proportional-hazards model for progression-free (PFS) and overall (OS) survival.

\begin{tabular}{lccccc}
\hline & \multicolumn{2}{c}{ PFS } & & OS \\
\cline { 2 - 3 } & Multivariate HR (95\%CI) & $p$-Value & & Multivariate HR (95\%CI) & $p$-Value \\
\hline NLR & $2.214(1.04-4.74)$ & 0.040 & $3.225(1.34-7.76)$ & 0.009 \\
PS & $3.889(1.16-13.01)$ & 0.027 & $3.873(1.10-13.60)$ & 0.035 \\
Stage & $3.407(1.09-10.65)$ & 0.035 & $3.146(0.62-15.96)$ & 0.167 \\
TPS & $2.448(1.26-4.77)$ & 0.008 & & $1.187(0.49-2.86)$ & 0.703 \\
\hline
\end{tabular}

CI: Confidence interval; HR: hazard ratio; NLR: neutrophil-to-lymphocyte ratio; PS: Eastern Cooperative Oncology Group performance status; TPS: tumor proportion score.

Cellular factors involved in inflammation, including neutrophils and lymphocytes, are potential prognostic factors of NSCLC and other solid cancer types. An inflammatory response against cancer is associated with the production of various chemokines and the induction of inflammatory cells such as neutrophils, which promote the secretion of inflammatory cytokines interleukin-1/6, and tumor necrosis factor $\alpha$, and vascular endothelial growth factors, which promote angiogenesis and ultimately promote the proliferation and metastasis of cancer cells and mediate resistance to apoptosis $(16,17)$. Peripheral neutrophil counts are directly related to intratumoral neutrophils (18) and higher neutrophil counts are correlated to reduced $\mathrm{CD} 8^{+} \mathrm{T}-$ lymphocyte counts in NSCLC (19). Thus, lymphopenia reflects an impaired cellular immune response (20). Based on these findings and evidence in the literature, NLR reflects the degree of local neutrophil and lymphocyte infiltration independently of PD-L1 expression and may reflect the efficacy of PD1 antibody monotherapy but not anti-PD-L1 monotherapy.

There are some limitations to this study. Firstly, this was a retrospective study with a small sample size that may have led to potential bias and confounding factors. Therefore, additional studies with larger sample sizes are necessary to confirm our findings. Secondly, this study did not evaluate immune reaction in tumor and did not compare NLR at the tumor site and of peripheral blood; future studies should be aware of addressing this issue. 


\section{Conclusion}

In conclusion, a high NLR in the pre-treatment stage was associated with significantly short PFS and OS of patients with previously untreated, high-PD-L1-expressing NSCLC who underwent pembrolizumab monotherapy. This finding may be helpful to identify patients who will poorly respond to pembrolizumab monotherapy even if TPS is $\geq 50 \%$.

\section{Conflicts of Interest}

Makoto Nishio reports honoraria from Ono, BMS, Pfizer, Chugai, Taiho Pharmac, AstraZeneca, Boehringer-ingelheim, MSD, and Novartis, research funding from Novartis, Daiichi Sankyo, Taiho Pharma, BMS, Boehringer-ingelheim, Ono Pharmaceutical, Eli Lilly, Chugai, AstraZeneca, Merck Sernon, MSD and Pfizer. Noriko Yanagitani reports employment/leadership position/advisory role of Chugai Phrmaceutical. Atsushi Horiike reports horaria from chugai pharma, AstraZeneca, Pfizer, Ono Pharmaceutical, Bristol-Myers Squibb Japan, A2 Healthcare and MSD oncology, research funding from Chugai Pharma, MSD Oncology, Abbvie, AstraZeneca and Loxo.

\section{Authors' Contributions}

Tsukasa Hasegawa is the main author of the article. Tsukasa Hasegawa, Noriko Yanagitani and Makoto Nishio were involved in study concept, design, statistical analysis of patient data and writing of the article. Tsukasa Hasegawa, Noriko Yanagitani, Hirofumi Utsumi, Hiroshi Wakui, Hiroaki Sakamoto, Takehiro Tozuka, Hiroshi Yoshida, Yoshiaki Amino, Shinya Uematsu, Takahiro Yoshizawa, Ken Uchibori, Satoru Kitazono, Atsushi Horiike, Takeshi Horai and Kazuyoshi Kuwano were involved in patient clinical data collection. All Authors read and approved the final article before submission.

\section{Acknowledgements}

The Authors thank all the study participants who provided clinical data for the analysis.

\section{References}

1 Siegel RL, Miller KD and Jemal A: Cancer statistics, 2017. CA Cancer J Clin 67(1): 7-30, 2017. PMID: 28055103. DOI: $10.3322 /$ caac. 21387

2 Brahmer J, Reckamp KL, Baas P, Crino L, Eberhardt WE, Poddubskaya E, Antonia S, Pluzanski A, Vokes EE, Holgado E, Waterhouse D, Ready N, Gainor J, Aren Frontera O, Havel L, Steins M, Garassino MC, Aerts JG, Domine M, Paz-Ares L, Reck M, Baudelet C, Harbison CT, Lestini B and Spigel DR: Nivolumab versus docetaxel in advanced squamous-cell nonsmall-cell lung cancer. N Engl J Med 373(2): 123-135, 2015. PMID: 26028407. DOI: 10.1056/NEJMoa1504627

3 Herbst RS, Baas P, Kim D-W, Felip E, Pérez-Gracia JL, Han JY, Molina J, Kim J-H, Arvis CD, Ahn M-J, Majem M, Fidler MJ, de Castro G, Garrido M, Lubiniecki GM, Shentu Y, Im E,
Dolled-Filhart $\mathrm{M}$ and Garon EB: Pembrolizumab versus docetaxel for previously treated, PD-L1-positive, advanced nonsmall-cell lung cancer (KEYNOTE-010): A randomised controlled trial. Lancet 387(10027): 1540-1550, 2016. PMID: 26712084. DOI: 10.1016/s0140-6736(15)01281-7

4 Reck M, Rodriguez-Abreu D, Robinson AG, Hui R, Csoszi T, Fulop A, Gottfried M, Peled N, Tafreshi A, Cuffe S, O'Brien M, Rao S, Hotta K, Leiby MA, Lubiniecki GM, Shentu Y, Rangwala $R$ and Brahmer JR, for the KEYNOTE-042 Investigators: Pembrolizumab versus chemotherapy for PD-L1positive non-small-cell lung cancer. N Engl J Med 375(19): 1823-1833, 2016. PMID: 27718847. DOI:10.1056/NEJMoa 1606774

5 Rittmeyer A, Barlesi F, Waterkamp D, Park K, Ciardiello F, von Pawel J, Gadgeel SM, Hida T, Kowalski DM, Dols MC, Cortinovis DL, Leach J, Polikoff J, Barrios C, Kabbinavar F, Frontera OA, De Marinis F, Turna H, Lee J-S, Ballinger M, Kowanetz M, He P, Chen DS, Sandler A and Gandara DR, for the OAK Study Group: Atezolizumab versus docetaxel in patients with previously treated non-small-cell lung cancer (OAK): A phase 3, open-label, multicentre randomised controlled trial. The Lancet 389(10066): 255-265, 2017. PMID: 27979383. DOI: 10.1016/s0140-6736(16)32517-x

6 Gandhi L, Rodriguez-Abreu D, Gadgeel S, Esteban E, Felip E, De Angelis F, Domine M, Clingan P, Hochmair MJ, Powell SF, Cheng SY, Bischoff HG, Peled N, Grossi F, Jennens RR, Reck M, Hui R, Garon EB, Boyer M, Rubio-Viqueira B, Novello S, Kurata T, Gray JE, Vida J, Wei Z, Yang J, Raftopoulos H, Pietanza MC and Garassino MC, for the KEYNOTE-189 Investigators: Pembrolizumab plus chemotherapy in metastatic non-small-cell lung cancer. N Engl J Med 378(22): 2078-2092, 2018. PMID: 29658856. DOI: 10.1056/NEJMoa1801005

7 Mok TSK, Wu Y-L, Kudaba I, Kowalski DM, Cho BC, Turna HZ, Castro G, Srimuninnimit V, Laktionov KK, Bondarenko I, Kubota K, Lubiniecki GM, Zhang J, Kush D and Lopes G, for the KEYNOTE-042 Investigators: Pembrolizumab versus chemotherapy for previously untreated, PD-L1-expressing, locally advanced or metastatic non-small-cell lung cancer (KEYNOTE-042): A randomised, open-label, controlled, phase 3 trial. The Lancet 393(10183): 1819-1830, 2019. PMID: 30955977. DOI: 10.1016/s0140-6736(18)32409-7

8 Paz-Ares L, Luft A, Vicente D, Tafreshi A, Gumus M, Mazieres J, Hermes B, Cay Senler F, Csoszi T, Fulop A, Rodriguez-Cid J, Wilson J, Sugawara S, Kato T, Lee KH, Cheng Y, Novello S, Halmos B, Li X, Lubiniecki GM, Piperdi B and Kowalski DM, for the KEYNOTE-407 Investigators: Pembrolizumab plus chemotherapy for squamous non-small-cell lung cancer. N Engl J Med 379(21): 2040-2051, 2018. PMID: 30280635. DOI: 10.1056/NEJMoa1810865

9 Weide B, Martens A, Hassel JC, Berking C, Postow MA, Bisschop K, Simeone E, Mangana J, Schilling B, Di Giacomo AM, Brenner N, Kahler K, Heinzerling L, Gutzmer R, Bender A, Gebhardt C, Romano E, Meier F, Martus P, Maio M, Blank C, Schadendorf D, Dummer R, Ascierto PA, Hospers G, Garbe $\mathrm{C}$ and Wolchok JD: Baseline biomarkers for outcome of melanoma patients treated with pembrolizumab. Clin Cancer Res 22(22): 5487-5496, 2016. PMID: 27185375. DOI: 10.1158/ 1078-0432.CCR-16-0127

10 Eisenhauer EA, Therasse P, Bogaerts J, Schwartz LH, Sargent $\mathrm{D}$, Ford R, Dancey J, Arbuck S, Gwyther S, Mooney M, 
Rubinstein L, Shankar L, Dodd L, Kaplan R, Lacombe D and Verweij J: New response evaluation criteria in solid tumours: Revised RECIST guideline (version 1.1). Eur J Cancer 45(2): 228-247, 2009. PMID: 19097774. DOI: 10.1016/j.ejca 2008.10.026

11 Bilen MA, Martini DJ, Liu Y, Lewis C, Collins HH, Shabto JM, Akce M, Kissick HT, Carthon BC, Shaib WL, Alese OB, Pillai RN, Steuer CE, Wu CS, Lawson DH, Kudchadkar RR, El-Rayes BF, Master VA, Ramalingam SS, Owonikoko TK and Harvey RD: The prognostic and predictive impact of inflammatory biomarkers in patients who have advanced-stage cancer treated with immunotherapy. Cancer 125(1): 127-134, 2019. PMID: 30329148. DOI: $10.1002 / \mathrm{cncr} .31778$

12 Capone M, Giannarelli D, Mallardo D, Madonna G, Festino L, Grimaldi AM, Vanella V, Simeone E, Paone M, Palmieri G, Cavalcanti E, Caraco C and Ascierto PA: Baseline neutrophilto-lymphocyte ratio (NLR) and derived NLR could predict overall survival in patients with advanced melanoma treated with nivolumab. J Immunother Cancer 6(1): 74, 2018. PMID: 30030012216. DOI: 10.1186/s40425-018-0383-1

13 Lalani AA, Xie W, Martini DJ, Steinharter JA, Norton CK, Krajewski KM, Duquette A, Bosse D, Bellmunt J, Van Allen EM, McGregor BA, Creighton CJ, Harshman LC and Choueiri TK: Change in neutrophil-to-lymphocyte ratio (NLR) in response to immune checkpoint blockade for metastatic renal cell carcinoma. J Immunother Cancer 6(1): 5, 2018. PMID: 329353553. DOI: 10.1186/s40425-018-0315-0

14 Jiang T, Bai Y, Zhou F, Li W, Gao G, Su C, Ren S, Chen X and Zhou C: Clinical value of neutrophil-to-lymphocyte ratio in patients with non-small-cell lung cancer treated with PD1/PDL1 inhibitors. Lung Cancer 130: 76-83, 2019. PMID: 30885355. DOI: 10.1016/j.lumgcan.2019.02.009

15 Rajendran P, Chen YF, Chen YF, Chung LC, Tamilselvi S, Shen CY, Day CH, Chen RJ, Viswanadha VP, Kuo WW and Huang CY: The multifaceted link between inflammation and human diseases. J Cell Physiol 233(9): 6458-6471, 2018. PMID: 29323719. DOI: $10.1002 /$ jcp.26479
16 Balkwill $\mathrm{F}$ and Mantovani A: Inflammation and cancer: Back to Virchow? The Lancet 357(9255): 539-545, 2001. PMID: 11229684. DOI: $10.1016 / \mathrm{S} 0140-6736(00) 04046-0$

17 Koizumi K, Hojo S, Akashi T, Yasumoto K and Saiki I: Chemokine receptors in cancer metastasis and cancer cellderived chemokines in host immune response. Cancer Sci 98(11): 1652-1658, 2007. PMID: 17894551. DOI: 10.1111/ j.1349-7006.2007.00606.x

18 Moses K and Brandau S: Human neutrophils: Their role in cancer and relation to myeloid-derived suppressor cells. Semin Immunol 28(2): 187-196, 2016. PMID: 2706179. DOI: 10.1016/j.smim.2016.03.018

19 Kargl J, Busch SE, Yang GH, Kim KH, Hanke ML, Metz HE, Hubbard JJ, Lee SM, Madtes DK, McIntosh MW and Houghton AM: Neutrophils dominate the immune cell composition in nonsmall cell lung cancer. Nat Commun 8: 14381, 2017. PMID: 28146145. DOI: $10.1038 /$ ncomms 14381

20 Gooden MJ, de Bock GH, Leffers N, Daemen T and Nijman HW: The prognostic influence of tumour-infiltrating lymphocytes in cancer: A systematic review with meta-analysis. Br J Cancer 105(1): 93-103, 2011. PMID: 21629244. DOI: 10.1038/bjc.2011.189
Received October 7, 2019

Revised October 22, 2019

Accepted October 30, 2019 